\title{
A LONG-RANGE ATMOSPHERIC TRANSPORT MODEL (HY-SPLIT) FOR ENVIRONMENTAL EMERGENCY RESPONSE (EER): EVALUATION OF DRIVING MODELS
}

\author{
J.H. Vermeulen and M.T. Freiman* \\ South African Weather Service, Private Bag X097, Pretoria 0001 \\ *Climatology Research Group, University of the Witwatersrand, P.O WITS 2050, Johannesburg
}

\begin{abstract}
The Eta and Aviation (AVN) driving models of HY-SPLIT are evaluated by means of a case study of the sulphur fire plume at Somerset West (34 $\left.04^{\prime} \mathrm{S}, 18^{\circ} 48^{\prime} \mathrm{E}\right)$ which caused sulphur dioxide $\left(\mathrm{SO}_{2}\right)$ air pollution over Macassar on 16 17 December 1995. The HY-SPLIT model is verified by comparing it with the Lagrangian kinematic trajectory (LKT) model. Plume dispersions and depositions of the HY-SPLIT model for the Eta and AVN driving models are compared with Eta model winds. Eta model winds for a grid point close to the fire are verified against radiosonde data and synoptic observations. Results indicate that the finer-resolution regional Eta model has the higher accuracy.
\end{abstract}

\section{INTRODUCTION}

The HY-SPLIT (HYbrid-Single Particle Lagrangian Integrated Trajectory) model is a complete system for computing simple trajectories to complex dispersion and deposition simulations using a particle approach. Calculations are performed sequentially on multiple meteorological grids using either archive or forecast data fields (Draxler, 1992; 1994). The model is driven by a Eulerian General Circulation Model such as the National Centres for Environmental Prediction's (NCEP) Eta numerical weather prediction model in daily operation at the South African Weather Bureau (SAWB) (Poolman et al., 1994). A driving model provides initial and boundary values for the trajectory model.

The HY-SPLIT model is designed to provide a response to emergencies such as the long-range transport, diffusion and deposition of radioactive material and other hazardous gases in an operational setting. Environmental Emergency Response is a World Meteorological Organization (WMO) initiative for National Meteorological Services. A regional specialised EER system has been developed at the SAWB (Vermeulen, 1997) for WMO Region 1 (Africa) which uses an Aviation model (AVN) with a horizontal resolution of $100 \mathrm{~km}$ and 28 sigma levels to drive HY-SPLIT. For the southern African area of WMO Region I a limited area Eta model with horizontal resolution of $80 \mathrm{~km}$ and 38 vertical levels will be used to drive HYSPLIT.

The driving models are evaluated by means of a case study of the Sulphur fire plume on 16-17 December 1995 at Somerset West (Western Cape Province) which caused $\mathrm{SO}_{2}$ pollution over Macassar. Hundreds of people had to be evacuated out of Macassar. Plume dispersions of HY-SPLIT are compared with actual radiosonde data and synoptic observations. A case study of the release of a gas such as $\mathrm{SO}_{2}$ in South Africa will help to establish long-range atmospheric transport modelling as a useful weather prediction product for EER in South Africa as well as internationally. In this paper 'longrange' refers to the synoptic spatial scale, and predictions are done for a lead-time of 48 hours. Unless otherwise indicated, all times quotes are in South African Standard Time.

\section{CASE STUDY \\ Background}

Macassar $\left(34^{\circ} \quad 03^{\prime} \mathrm{S}, 18^{\circ} \quad 45^{\prime} \mathrm{E}\right)$ lies $3.6 \mathrm{~km}$ north-northwest of the African Explosives and Chemicals Industries plant where the sulphur fire $\left(34^{\circ} 04^{\prime} \mathrm{S}, 18^{\circ} 48^{\prime} \mathrm{E}\right)$ occurred (Fig. 1). A series of veld fires to the southeast of the sulphur stock pile preceded the sulphur fire from 13 - 16 December 1995 and were fanned by a southeasterly wind (Desai, 1997). MidDecember is well into the heart of the fire danger season for southwestern Cape. The fire danger index on 16 December 1995 was in the very dangerous category, with mean wind speeds of $8.5 \mathrm{~m} / \mathrm{s}$ for that day as well as very dry conditions. The mean wind speed peaked to 13.4 $\mathrm{m} / \mathrm{s}$ on 16 December 1995 from 15:00-16:00, with a maximum gust of $20 \mathrm{~m} / \mathrm{s}$ at 15:40. The 14:00 synoptic weather map on 16 December is depicted in Fig. 2 and shows strong southeasterly flow over southwestern Cape. 


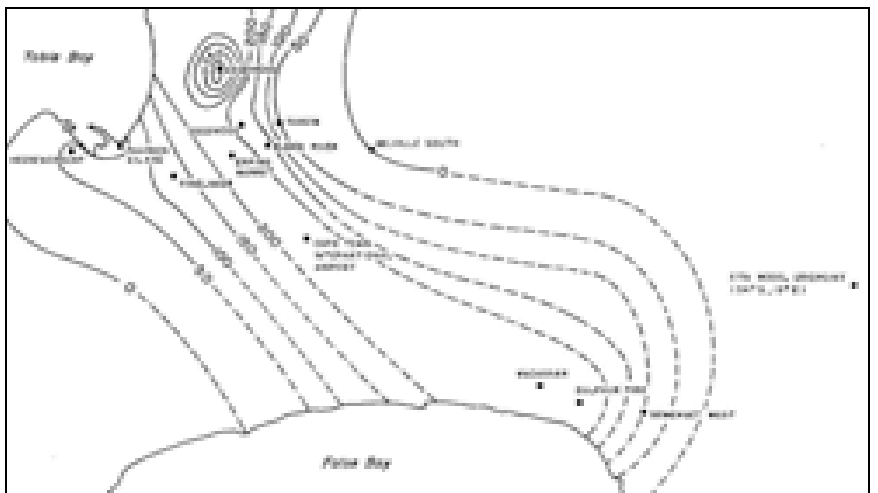

Figure 1: $\mathrm{SO}_{2}$ concentration $\left(\mu \mathrm{g} / \mathrm{m}^{3}\right)$ for 15 to 19 December 1995

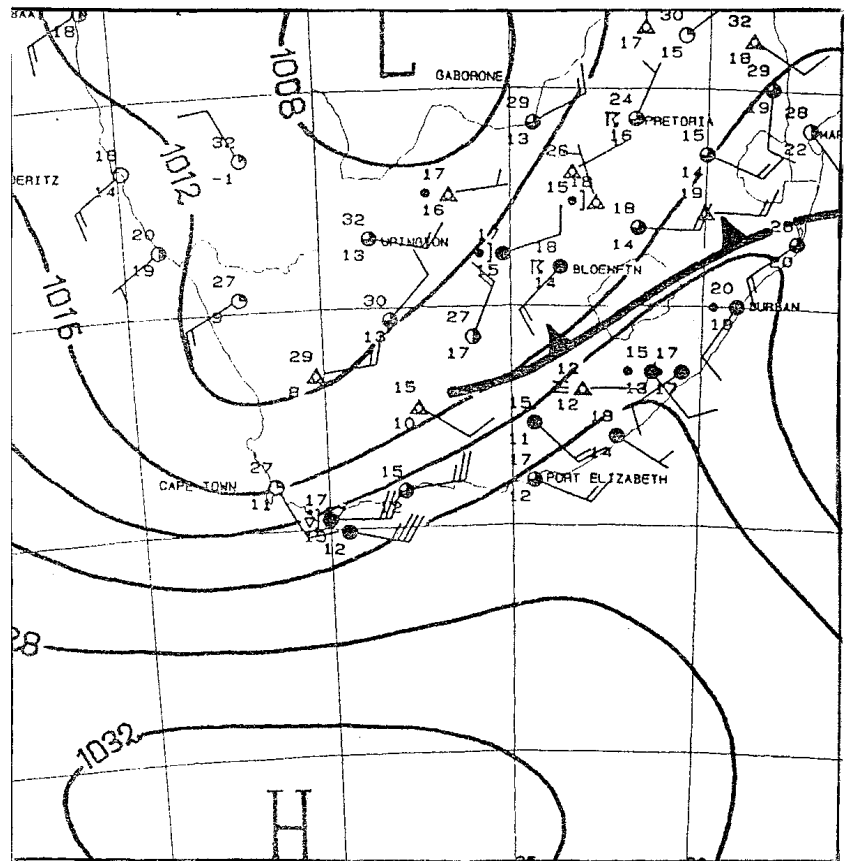

Figure 2: Synoptic chart for 12:00 UT 16 December 1995

The sulphur stockpile started burning at 18:20 on 16 December 1995 and was only extinguished at 15:22 on 17 December 1995. The fire burned for 21 hours and released approximately 14000 metric tons of $\mathrm{SO}_{2}$ into the atmosphere. According to Prof. Batterman's plume dispersion model (Desai, 1997) the plume reached Macassar because of the steady southeasterly wind. $\mathrm{SO}_{2}$ concentrations were recorded as 20 - 200 particles per million (ppm), averaging $100 \mathrm{ppm}$, which are far above World Health Organization limits for human exposure.

\section{Driving models}

Eta model: The Eta mountain step vertical coordinate model with data sets initialised at 0000 UT on 16 and 17 December 1995 is used. This HY-SPLIT/Eta model calculation method is a hybrid between Eulerian and Lagrangian approaches (Draxler and Hess, 1997). A single pollutant is advected and diffused in a Lagrangian framework while the concentrations are calculated on a fixed Eulerian grid. Meteorologically-gridded analysis and forecast fields are used for initial and boundary conditions. The initial and boundary value data for HY-SPLIT consists of 12- and 18-hour forecasts from 16 December 1995 and 6-hourly forecasts until 36-hours from 17 December 1995. Eta model input for HY-SPLIT has 18 vertical levels which consist of the pressure, temperature, total precipitation and mean sea level pressure variables at the surface and the $\mathrm{u}$, $\mathrm{v}$ (the horizontal wind components), w (the vertical wind component), geopotential heights, temperature and specific humidity parameters for every $50 \mathrm{hPa}$ from $1000 \mathrm{hPa}$ to $200 \mathrm{hPa}$. The horizontal resolution of the Eta model is $80 \mathrm{~km}$. Eta model data in PCST-NOAA format is converted to ARL-PACKED format for use by HY-SPLIT.

AVN model: The Air Resources Laboratory of the National Oceanic and Atmospheric Administration's (NOAA) AVN model is an additional driving model. The initial and boundary value data for HY-SPLIT consist of 6hourly analyses from $0000 \mathrm{UT}$ on the 16 December to 0000 UT on the 19 December, 1995. The horizontal resolution of the AVN model is $191 \mathrm{~km}$. The AVN model input for HY-SPLIT comprises 14 vertical levels which consist of the pressure, temperature at $2 \mathrm{~m}$, total precipitation and mean sea level pressure variables at the surface and the $\mathrm{u}, \mathrm{v}$ (the horizontal wind components), w (the vertical wind component), geopotential heights, temperature and specific humidity parameters at $1000,925,850,700 \ldots 250,200,150,100,50$ and $20 \mathrm{hPa}$ levels.

The verification of the HY-SPLIT model with the Lagrangian kinematic trajectory (LKT) model

The LKT model makes use of three-dimensional wind velocity vectors $-u$ and $v$ in the horizontal and $w$ in the vertical, prepared by NCEP. The 6hourly velocity vectors of the starting point of the trajectory are ascertained through linear interpolation from the nearest NCEP driving model grid point. Interpolation of the point of origin is facilitated within a $2.5^{\circ} \times 2.5^{\circ} \times 50-100$ $\mathrm{hPa}$ volume, representing the three-dimensional grid size of the NCEP data. Thereafter, the 
trajectories are run for an advection time period of 60 minutes where the advection is calculated, using the explicit method of integration, from:

$$
\mathrm{x}(\mathrm{t}+\mathrm{Dt})=\mathrm{x}(\mathrm{t})+\mathrm{V}[\mathrm{x}(\mathrm{t})] \mathrm{Dt},
$$

where $t$ is the starting time, $D t$ is the time step, $x$ $(t+D t)$ is the position of the air parcel at time $t$ $+D t, x(t)$ is the position of the air parcel the previous time step, and $\mathrm{V}$ is the wind vector of the parcel (D'Abreton, 1996). The advection process is repeated until the desired final time has been reached. Alternatively, the process was terminated when the parcel reached the boundaries of the dataset. The trajectory model utilises a terrain-following routine. Assumptions that the effects of wind shear and vorticity are negligible are made when using this model. Furthermore, it is assumed that no vertical mixing occurs. A three-dimensional 2-day forward trajectory was calculated from 00:00 UT 16 December, 1995 starting at the location of the sulphur fire.

\section{HY-SPLIT model input parameters}

The time of release from a height of $1 \mathrm{~m}$ above ground level (AGL) is 16:20 UT on 16 December 1995 and the release duration is 21 hours. The amount of $\mathrm{SO}_{2}$ released is 666 metric ton/ $\mathrm{hr}$. The source location is $34^{\circ} 04^{\prime} \mathrm{S}$ and $18^{\circ}$ $48^{\prime} \mathrm{E}$. The model top is set at $10 \mathrm{~km}$ AGL. The lattitudinal and longitudinal concentration grid spacing is $0.5^{\circ}$ and the grid span is $50^{\circ}$ in either direction. The four vertical concentration levels are 0,100, 200 and 300m AGL. The 0 level indicates that deposition is active. Henry's constant, which defines the wet removal process for soluble gases, is $1.3 \times 10^{4}$ (Molar/atm) for $\mathrm{SO}_{2}$. A pollutant resuspension factor of $10^{6} / \mathrm{m}$ is used.

\section{RESULTS}

Trajectory calculations from the HY-SPLIT and LKT models conform to the synoptic conditions depicted in Fig. 2. Furthermore, they all illustrate the transport of $\mathrm{SO}_{2}$ from Somerset West, past Macassar, and out into the Atlantic Ocean (Fig. 3). Two-day forward trajectories starting at $1000 \mathrm{hPa}$ on 16 December, 1995 at 0000 UT, run using the HY-SPLIT/AVN and the Lagrangian kinematic model indicate identical transport paths for the first 15 hours, very similar paths for the next 8 hours, and a diverging path for the remaining 25 hours, whereby the HY-SPLIT/AVN model trajectory advects directly east onshore and the kinematic trajectory advects northwards for a few more hours prior to moving onshore (Fig 3). The HYSPLIT/Eta model trajectory, in contrast, which starts from the same height $(1000 \mathrm{hPa})$ and at the same time (00:00 UT) illustrates localisedto regional-scale cyclonic recirculation as the air parcel returns to the southwestern coast of South Africa within 36 hours (Fig. 3).

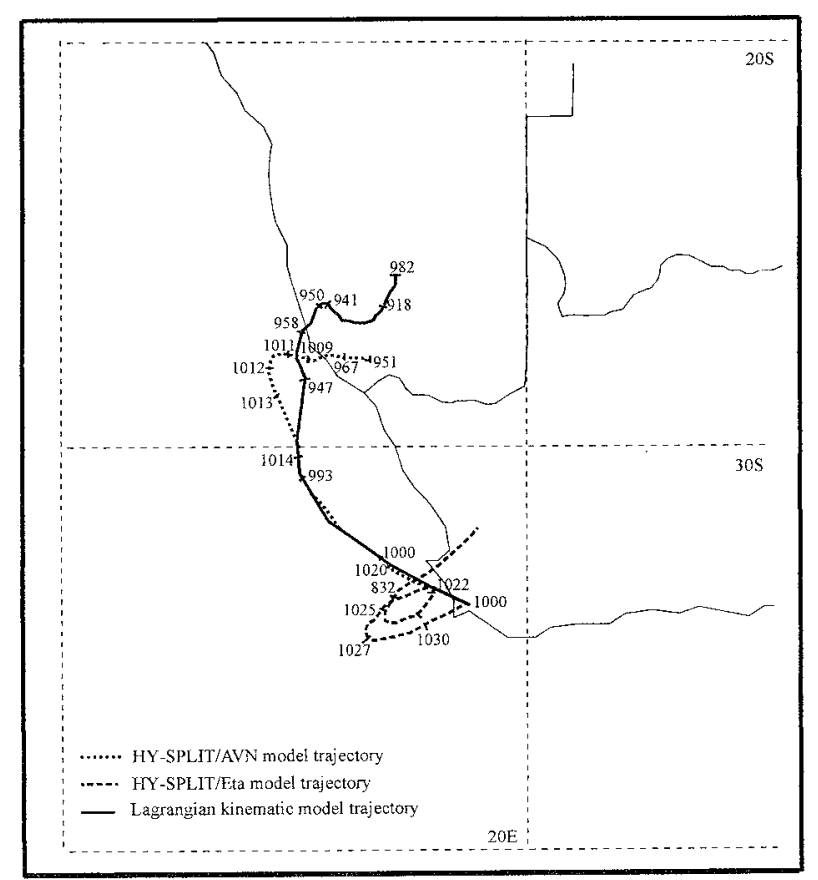

Figure 3: Two-day forward trajectories from Somerset West starting at 00:00UT 16 December 1995. The heights (hPa) of the trajectories are illustrated every 6 hours.

Air quality measurements verifying the sulphur fire were obtained for the Cape Town area from the air pollution monitoring directorate of the South African Department of Environmental Affairs and Tourism (Pers. Comm., 1996). The $\mathrm{SO}_{2}$ concentrations for the period 15 to 19 December 1995 are depicted in Fig. 1 and indicate higher concentrations downwind from the sulphur fire. The $\mathrm{SO}_{2}$ concentrations (not shown here) were considerably lower prior to and proceeding the fire. Prof. Batterman's model (Desai, 1997) predicts a $271000 \mu \mathrm{g} \cdot \mathrm{m}^{-3}$ maximum concentration at Macassar, while the HY-SPLIT model predicts $>13 \mu \mathrm{g} . \mathrm{m}^{-3}$ over the whole area due to the coarser horizontal resolution of the driving models.

Air concentration forecasts of $\mathrm{SO}_{2}$ expressed as average exposure from ground to $500 \mathrm{~m}$ (Ton

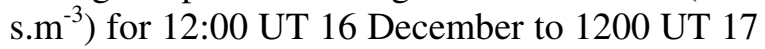
December are presented in Fig. $4 \mathrm{a}$ and $4 \mathrm{~b}$ for the HY-SPLIT/Eta and HY-SPLIT/AVN driving models respectively. The plumes lie eastwards of the source for both models and there is fair 
agreement between them. Eta mean sea level winds for the 17 December, 1995 analysis and 12 hour forecast, depicted in Fig. 5a and 5b respectively, show an easterly flow at the source location and confirm the HY-SPLIT/Eta model's plume dispersion.
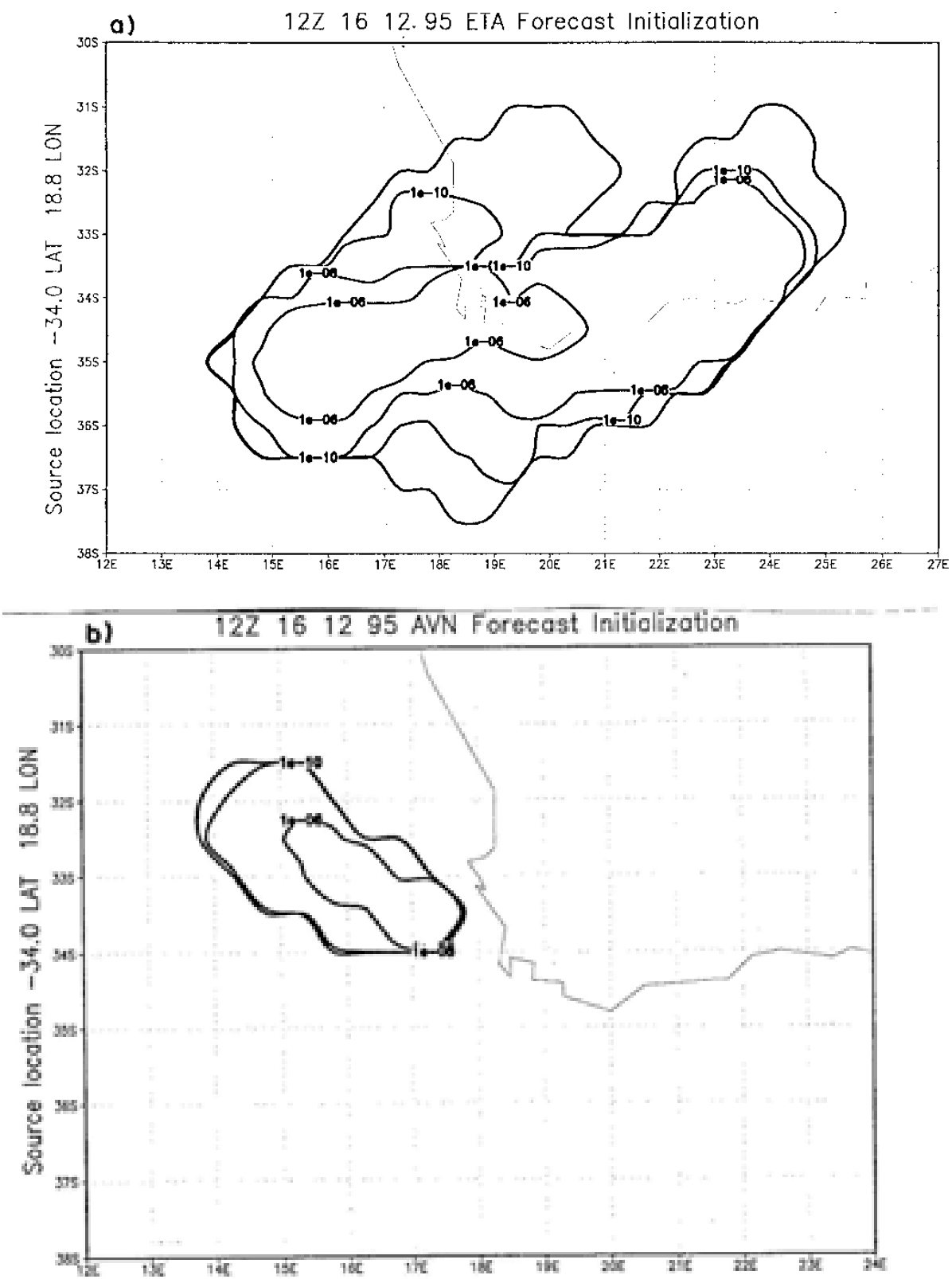

Figure 4: $\mathrm{SO}_{2}$ concentration forecast of $\mathrm{HY}-\mathrm{SPLIT}$ as average exposure from ground to $500 \mathrm{~m}\left(\mathrm{Ton}^{\left.\mathrm{S} . \mathrm{m}^{-3}\right)}\right.$ for 12:00 UT 16 December to 12:00 UT 17 December for driving model a) Eta and b) AVN

a.

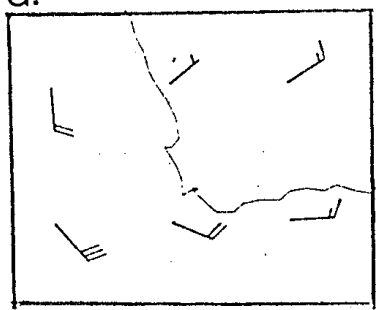

b.

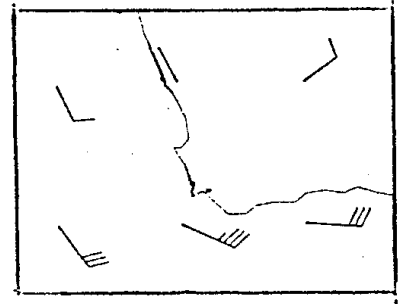

C.

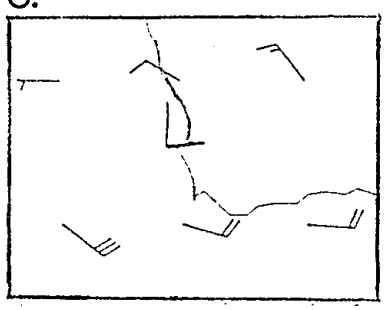

d.

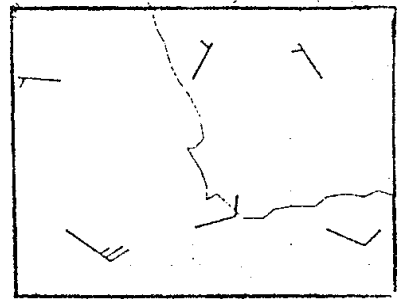

Figure 5: Eta model surface wind fields of the 00:00UT 17 December 1995 run for a) analysis, b) 12 hour forecast, c) 24 hour forecast and d) 36 hour forecast (speed in knots). 
Air concentration forecasts of $\mathrm{SO}_{2}$ expressed as the average exposure from ground to $500 \mathrm{~m}$ (Ton $\mathrm{s} / \mathrm{m}^{3}$ ) for 12:00 UT 17 December to 12:00 UT 18 December are presented in Fig. 6a and 6b for the Eta and AVN driving models respectively. The HY-SPLIT/Eta model plume lies further westwards but has also spread eastwards due to the cyclonic flow over $\mathrm{St}$ Helena Bay (see Fig. 5c and 5d which depict mean sea level winds for the 24 and 36 hour forecasts of Eta). The HY-SPLIT/AVN model plume is mostly north-westward as can be expected for this coarser vertical and horizontal resolution model. The AVN data on standard pressure heights has four levels in the boundary layer, from the surface to $700 \mathrm{hPa}$ (Stull, 1988), while the Eta data for every $50 \mathrm{hPa}$ pressure height has eight levels.
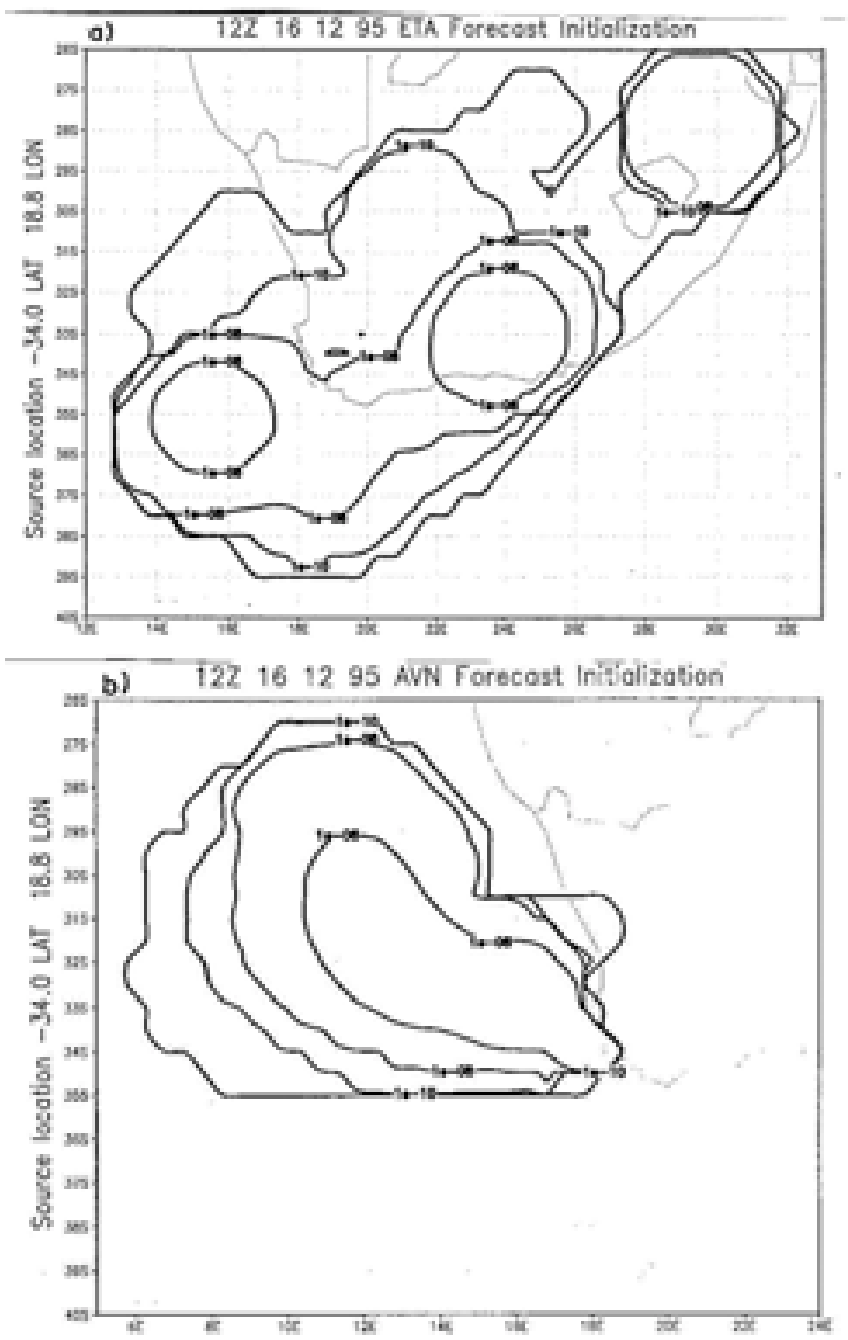

Figure 6: $\mathrm{SO}_{2}$ concentration forecast of HY-SPLIT as average exposure from ground to $500 \mathrm{~m}$ (Ton S.m ${ }^{3}$ ) for 12:00 UT 17 December to 12:00 UT 18 December for driving model a) Eta and b) AVN

Ground-level deposition forecasts of $\mathrm{SO}_{2}$ (in Ton $/ \mathrm{m}^{2}$ ) from 12:00 UT 16 December to $12: 00$
UT 18 December are presented in Fig. 7a and 7b for Eta and AVN driving models respectively. The deposition fields compare well on the maximum to the west of the source but disagree completely with regard to the maxima shown northeast of the source area by the Eta forecast. The depositions of the models compare very well with their day 2 air concentration forecasts (compare Fig.7a and 7b with Fig. $6 a$ and $6 b$ respectively). The difference between the deposition fields can be attributed to the coarser resolution of the AVN driving model when compared to the Eta driving model. Eta model precipitation forecast for the period 12:00 UT 16 December to $12: 00$ UT 18 December is presented in Fig. 8. When the Eta deposition forecast (Fig. 7a) is compared with the precipitation forecasts it is clear that the large deposition maximum to the northeast of the source can be ascribed to the cyclonic circulation and associated precipitation.
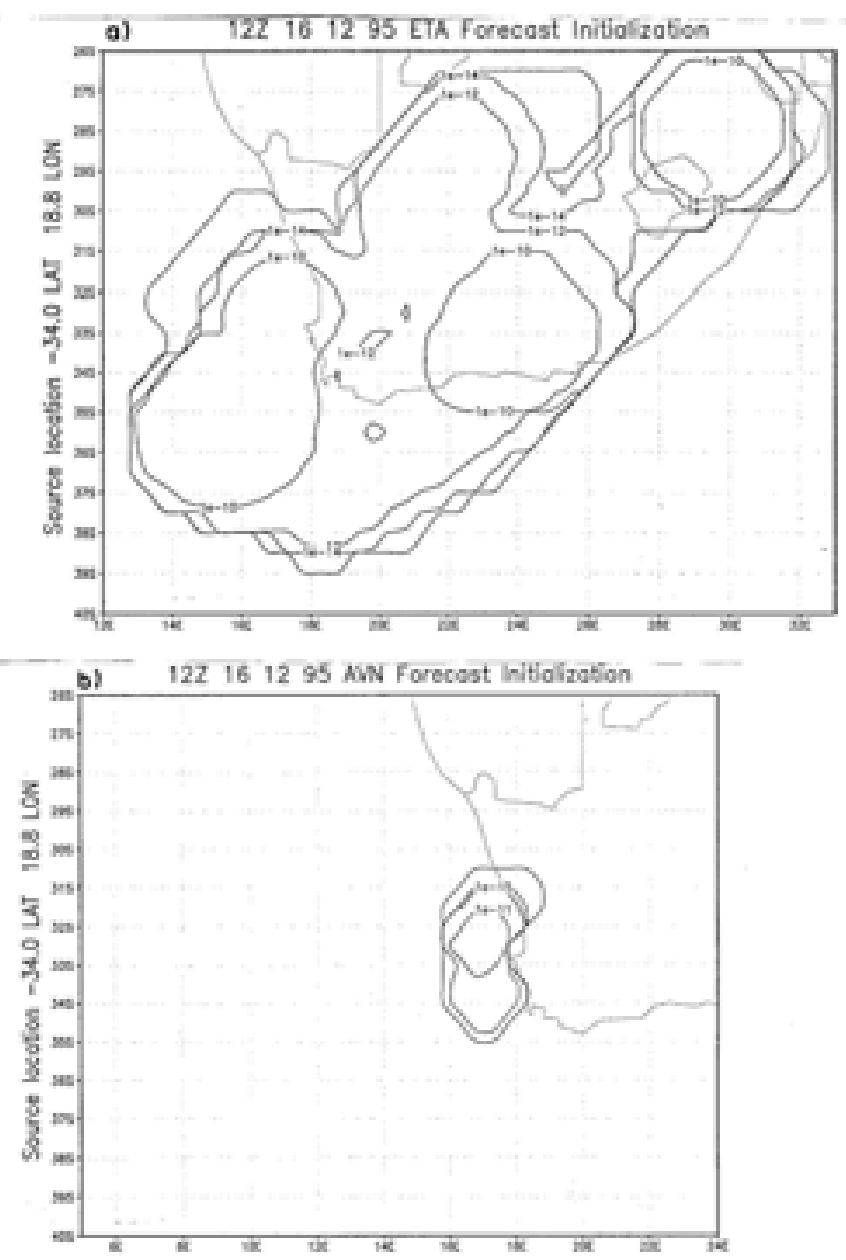

Figure 7: SO2 ground-level deposition forecast of HY-SPLIT as (Ton/m2) for 12:00 UT 16 December to 12:00 UT 17 December for driving model a) Eta and b) AVN 
Table 1 displays a comparison of Eta model winds at grid point $34^{\circ} \mathrm{S}, 19^{\circ} \mathrm{E}$ with Cape Town International Airport $\left(34^{\circ} \mathrm{S} ; 18.6^{\circ} \mathrm{E}\right)$ radiosonde winds every 12 hours from 12:00 UT on 16 December 1995 to $12: 00$ UT on 18 December 1995. Cape Town International Airport is $21 \mathrm{~km}$ northwest of the fire site. Radiosonde $1000 \mathrm{hPa}$ winds were taken from synoptic charts while 950, 900 and $800 \mathrm{hPa}$ winds correspond to the 2000, 3000 and 7000 feet winds respectively. Fig. 9 indicates that the Eta model wind forecast accuracy decreases with increasing lead-time.

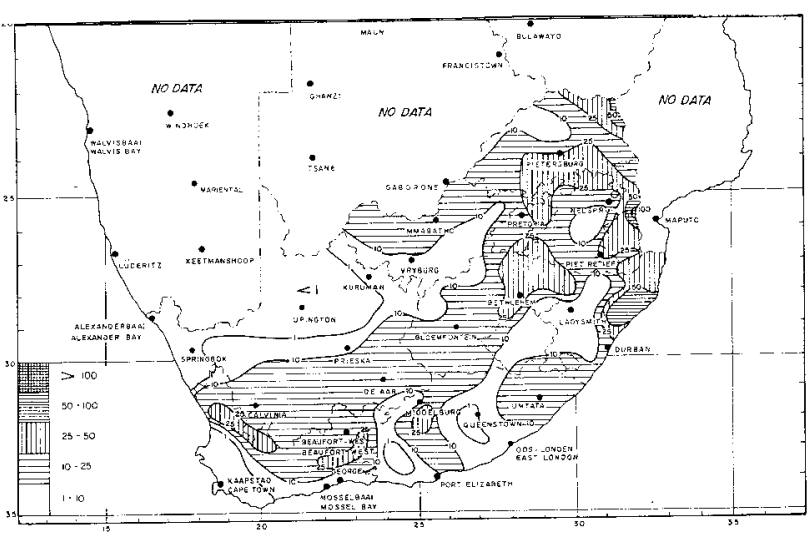

Figure 8: Eta model precipitation forecast in $\mathbf{~ m m}$ for 12:00 UT 16 December to 12:00 UT 18 December 1995

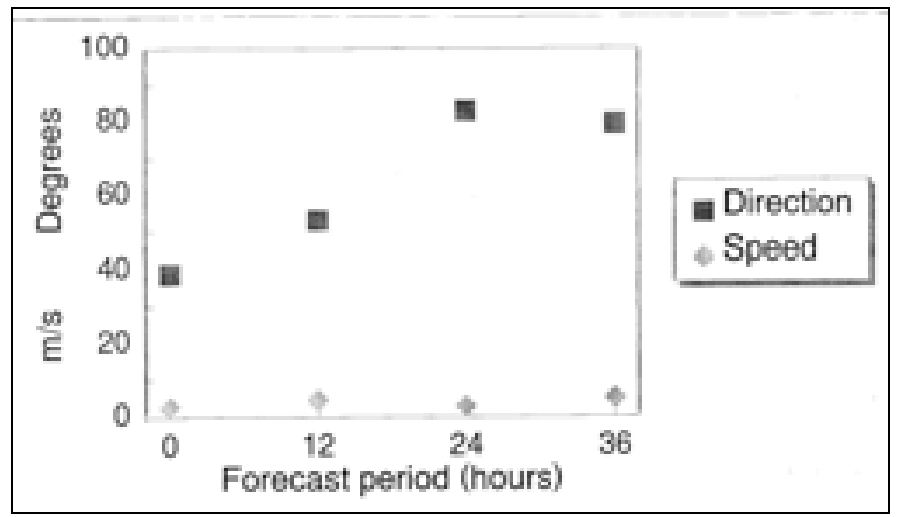

Figure 9: Mean absolute differences for Eta model upper air winds $\left(34^{\circ} \mathrm{S} 19^{\circ} \mathrm{E}\right)$ vs radiosonde for 12:00 UT 16 December to 12:00 UT 18 December 1995

TABLE 1: (a) A comparison of Eta model winds at grid point $\left(34^{\circ} \mathrm{S} ; 1^{\circ} \mathrm{E}\right)$ with Cape Town International Airport $\left(34^{\circ} \mathrm{S} ; 1^{18.6}{ }^{\circ} \mathrm{E}\right)$ radiosonde (T-phi) winds for 12:00 UT 16 December 1995 to 12:00 UT 18 December 1995 (wind speed in $\mathrm{m} / \mathrm{s}$ ).

\begin{tabular}{|c|c|c|c|c|c|c|c|c|c|c|}
\hline \multirow{2}{*}{$\begin{array}{l}\text { Level } \\
\text { (hPa) }\end{array}$} & \multicolumn{2}{|c|}{16 Dec 12:00 } & \multicolumn{2}{|c|}{17 Dec 00:00 } & \multicolumn{2}{|c|}{17 Dec 12:00 } & \multicolumn{2}{|c|}{18 Dec 00:00 } & \multicolumn{2}{|c|}{18 Dec 12:00 } \\
\hline & T-phi & Eta & T-phi & Eta & T-phi & Eta & T-phi & Eta & T-phi & Eta \\
\hline 1000 & $160 / 7$ & 19/12 & $260 / 5$ & $90 / 4$ & $180 / 7$ & $110 / 13$ & $200 / 2$ & $131 / 3$ & $280 / 5$ & $351 / 2$ \\
\hline 950 & $120 / 5$ & $100 / 13$ & $120 / 2$ & $79 / 7$ & $90 / 2$ & $93 / 8$ & $140 / 10$ & $323 / 3$ & $300 / 5$ & $317 / 4$ \\
\hline 900 & $110 / 2$ & $82 / 9$ & $80 / 5$ & $69 / 7$ & $110 / 2$ & $66 / 5$ & $130 / 7$ & & & $330 / 3$ \\
\hline 850 & $100 / 2$ & $58 / 8$ & $30 / 5$ & $48 / 8$ & $230 / 2$ & $35 / 5$ & $90 / 7$ & $318 / 4$ & $260 / 5$ & $340 / 2$ \\
\hline 800 & $350 / 5$ & $38 / 3$ & $300 / 7$ & $13 / 9$ & $240 / 2$ & $4 / 4$ & $70 / 7$ & $338 / 4$ & $240 / 7$ & Calm \\
\hline 700 & $100 / 5$ & $8 / 4$ & $310 / 10$ & $318 / 8$ & $30 / 2$ & $355 / 5$ & $70 / 10$ & $122 / 5$ & $270 / 12$ & $220 / 6$ \\
\hline 500 & $150 / 2$ & $4 / 2$ & $320 / 7$ & $328 / 7$ & $350 / 12$ & $7 / 8$ & $100 / 10$ & $93 / 12$ & $210 / 5$ & $140 / 6$ \\
\hline 400 & $340 / 2$ & $326 / 2$ & $310 / 7$ & $324 / 9$ & $340 / 10$ & $10 / 12$ & $40 / 10$ & $39 / 8$ & $150 / 7$ & $249 / 1$ \\
\hline 300 & $330 / 12$ & $298 / 5$ & $320 / 17$ & $329 / 26$ & $340 / 10$ & $347 / 25$ & $50 / 15$ & $11 / 15$ & $110 / 20$ & $2 / 3$ \\
\hline
\end{tabular}




\section{CONCLUSIONS}

The Eta and AVN models are assessed as driving models for the HY-SPLIT model. Both driving models illustrate the transport of $\mathrm{SO}_{2}$ from Somerset West, past Macassar and out into the Atlantic Ocean. The HY-SPLIT/AVN and LKT model calculations of two-day forward trajectories indicate identical transport paths for the first 15 hours and slight divergence thereafter. Trajectories calculated using the HYSPLIT/Eta and LKT model differ greatly in their transport paths. The trajectories output from the all three models conform to the prevailing synoptic conditions. The differences are due to the varying horizontal and vertical resolutions of each of the driving models: $80 \mathrm{~km}, 191 \mathrm{~km}$ and $250 \mathrm{~km}$, and $50 \mathrm{hPa}, 50-100 \mathrm{hPa}$ and 50-100 hPa for the HY-SPLIT/Eta, HY-SPLIT/AVN and LKT models, respectively.

The finer resolution HY-SPLIT/Eta model gives a more realistic presentation of the $\mathrm{SO}_{2}$ dispersion and deposition when compared to the HY-SPLIT/AVN model. The Eta model grid point winds compare well with the radiosonde winds at analysis time giving credibility to the HY-SPLIT model forecasts with Eta initial and boundary conditions.

\section{ACKNOWLEDGEMENTS}

Thanks is expressed to the Chief Director, Gert Schulze, the EER group leader Gerrie Coetzee, international consultant Roland Draxler, research manager Eugene Poolman and the staff of the Weather Bureau under whose guidance the project is being executed. Prof. P.D. Tyson is also thanked.

\section{REFERENCES}

D’Abreton P.C., 1996: Lagrangian kinematic and isentropic trajectory models for aerosol and trace gas transport studies in southern Africa, S.A. Jnl. Sc., 92, 157-160.

Desai S., 1997: Desai Commission of Inquiry into the Sulphur Fire at Somerset West Report, $132 \mathrm{pp}$.

Draxler R.R., 1992: HYbrid Single-Particle Lagrangian Integrated Trajectories (HY-SPLIT): version 3.0 - - User's Guide and Model Description, NOAA Technical Memorandum ERL ARL-195.

Draxler R.R., 1994: HY-SPLIT deposition module, NOAA Air Resources Laboratory, 1-16. Draxler R.R. and Hess G.D. 1997: An Overview of the HYSPLIT_4 Modelling System for Trajectories, Dispersion and Deposition, submitted to the Australian Meteorological Magazine.

Poolman E.R., Riphagen H.A., Sewell R.D. en Krige W.A., 1994: Die Eta-weervoorspelling model, Suid-Afrika, Weerburo Nuusbrief, Sept 94, p2-5.

Stull R.B., 1988: An Introduction to Boundary Layer Meteorology, Kluwer Academic Publishers, 666pp.

Vermeulen J.H., 1997: Implementation status report of the Environmental Emergency Response (EER) system for the SAWB, September 1997, Internal Report No. RES/50 